\title{
Institutional Challenges that affect Readiness for Access to Higher Education by Students with Disabilities(SWD) in Public universities in Kenya
}

\author{
Butalanyi Khakali Rebecca $^{1 *} \quad$ Dr Alice Limo ${ }^{2} \quad$ Prof. Patrick Acleus Kafu ${ }^{3}$ \\ 1.PhD candidate.,Department of Educational Management,University of Eldoret P.OBox121-30100, \\ Eldoret,Kenya \\ 2. Lecturer,Department of Educational Management,University of Eldoret, P.O Box 121-30100, Eldoret, Kenya \\ 3.Department of Curriculum and Instruction,University of Eldoret,P.O Box 121, 30100, Eldoret, Kenya
}

\begin{abstract}
Access to education implies an individual's presence, participation, acceptance and achievement in a learning institution.Kenya promotes education for all, but SWD are less than $1 \%$ of the enrolment in higher education(HE). This research presents challenges public universities experience in their pursuit for readiness to improve access to HE by students with disabilities (SWD). A case study basic qualitative research method of a descriptive nature is used because disability is about experiences of persons with disabilities(PWD) in relation to the environments they constantly interact with; the meaning they ascribe to the same and that it evidently affects a small percentage of the population.University administrators (Academic registrars and deans of students), SWD and lecturers who taught them at the time of the research comprised the target population. Sample participation encompassed 202 SWD, 46 lecturers and11 administrators, from 6 public universities. The tools of research were questionnaire for each of the target group, focus group discussion (FGD) for SWD and an observation checklist. Data analysis was done through IBM SPSS 23 computer package by use of descriptive statistics. Tables helped in the presentation of data. It was revealed that universities face challenges in their endeavor and process of being ready for access to H.E by SWD. Recommendation was that universities should adopt a Universal Design model in order to address these challenges.
\end{abstract}

Keywords: Institutional readiness, Access, Higher Education, Students with disabilities, challenges

DOI: $10.7176 / \mathrm{JEP} / 11-31-01$

Publication date: November $30^{\text {th }} 2020$

\section{Background to the Study}

Expanded opportunities to higher education for persons with disabilities( PWD) considerably add to their quality of life and that of their significant others (Wayne, 2004).Higher Education is the ultimate level of an individual's academic achievement and the first step towards professionalism. This is the level that is essential for meeting the manpower requirements of the highest caliber which is necessary for national development.Although it is evident that the higher the level of education of persons with disabilities, the better the chances for them to integrate into society is acknowledged; a study that was done in South Africa, found out that PWD are likely to drop out of school early (Matshedisho,2007).Education data in Kenya shows that a total of 2\% (224000) pupils with disabilities out of 10 million were in primary school while $0.4 \%$ (11219) out of 2.3 million were in secondary school ( Republic of Kenya 2007); the enrollment in the university was 461820; and out of this only $0.11691 \%$ (440) were SWD (Mukhwana, 2016).

There have been many deliberate interventions in the world in general and Kenya to address disability issues including access to education through legislation, yet as seen above, persons with disability seem not to be adequately accessing higher education. The UN Convention on the Right of Persons with Disabilities in Article Article 9(1) states that persons with disabilities should be enabled to live independently and participate fully in all aspects of life. Further elaboration directs that States Parties should take appropriate measures to ensure that persons with disabilities access, on an equal basis with others, to the physical environment, to transportation, to information and communications, including information and communications technologies and systems, and to other facilities and services open or provided to the public, both in urban and in rural areas. Article 24(1) gives an outline of the rights of PWD to education and what the countries of the world are required to do as pertains to implementation of the contents of the convention (UN CRPWD, 2006). In Kenya the Disability Act (2003) article 18(1), (2), (3) and articles 19 have given provisions for access to education for persons with disability. The same has been enshrined in the constitution of Kenya 2010 article 54(1) (b) where persons with disabilities must be able to access educational institutions and facilities for persons with disabilities that are integrated into society to the extent compatible with the interests of the person. The disability Act 2003 however provides a very general explanation of the discriminatory practices that are not allowed and calls for establishment of special schools and institutions for persons with disabilities.

Although these provisions are important, they can be improved further by identifying some key aspects that 
educational institutions, especially universities, ought to address to improve access to higher education for people with disabilities. Further the Act takes a charity and functional rather than a rights approach for access to education. It also lacks a compelling and implementation framework for the universities to be accountable. This leaves a loose end and gives universities a leeway to discriminate the disabled students.It is therefore not surprising to note that students with disabilities seem to be the least at reaching educational parity at all levels of schooling in Kenya.

The sustainable development goal(SDG) on education expresses that no part of the population is to be left out in accessing education by the year 2030(United Nations General Assembly, 2015). Kenya's economic and social strategic plan through its social pillar envisions a state where there will be a just and cohesive society with social equity living in a clean and secure environment with an average GDP growth rate of $10 \%$ per annum beginning from the year 2012 (Republic of Kenya (Vision 2030, 2008).

Despite all the efforts and legislative provision, PWD continue to be left out in accessing education in general and higher education in particular (Matshedisho,2007). They are more likely to face many barriers in their quest to access higher education than their normal peers(Githinji, 2015).

A combination of factors seems to affect access to higher education for PWD.The purpose of this research was to determine institutional Challenges that affect readiness for access to higher education by SWD in public universities in Kenya.

\subsection{Statement of the problem}

Available data shows that in Kenya $67 \%$ of PWD have attained a primary school level of education, 19\% and 2\% secondary and university level respectfully (Republic of Kenya,2007)).This points towards, their marginalization in accessing higher education. More data on education reveal these details; that $\%$ (224000) disabled pupils out of 10 million are in primary school while $0.4 \%$ (11219) out of 2.3 million are in secondary school (Republic of Kenya, 2016).At the same time university level representation is $0.11691 \%$ (440) SWD out of the total enrolment of 461820 are (Mukhwana, 2016). Definitely the enrolment of SWD at university level is lowest. Evidently therefore, access to higher education by SWD is a challenge because there is implication of high dropout rates and very low transition from one level to the next as observed from the data. The question that needs to be answered is why? How ready are the universities for access to education by students with disabilities?Are there some challenges that counter their readiness for access? If it is so what and where are they? This study sought to determine challenges faced by public universities towards readiness for access by students students with disability.

\subsection{Purpose of the study}

The purpose of this study is to determine the state of readiness for access (inclusion) to higher education by students with disabilities in Public Universities in Kenya

\subsection{Objective}

To determine challenges faced by public universities towards readiness for access to HE by students with disabilities

\subsection{Justification}

Globally about a billion people (15\%) live with disabilities. Approximately 150 million of these are children and the youth (WHO\&World Bank, 2011). The Sustainable Development Goal (UNDP, 2019) on Education projects that by the year 2030 every individual in the world should have accessed education and no one should be left out. Kenya's vision 2030 states that by 2030, every Kenyan should be living a high-quality life in a safe and clean environment while economic growth should be at 10\% GDP (Republic of Kenya, Vision 2030, 2008). It is imperative that achievement of this ambitious plan must not leave persons with disabilities behind. Logically then, HE institutions must strive to be ready to include. However there are bound to be challenges in their endeavour towards readiness for access to education by SWD. This research seeks to address these challenges.

\section{Literature Review}

This section concentrates on the literature review. The literature review sought to establish the status of readiness for access to Higher Education by students with disabilities (SWD) in Public Universities in Kenya and what challenges these institutions experience towards attaining the same.Literature review first considers the theoretical framework. The study was based on the social model of disability.

\subsection{The Social Model of Disability}

The pioneers of this model (Oliver,1990; Barnes,1999) view disability as a socially constructed phenomenon. The Social Model locates disability in society not in the individual. Instead, it identifies social prejudices inaccessible environments, discriminatory work arrangements and segregated education as disabling societal elements(Tshifhiwa,2016).In fact disability is a social organization (Barns; 1991). According to this model it is 
not individual limitations, of whatever kind, which are the cause of the problem of inaccessibility but society's failure to provide appropriate services and adequately ensure [that] the needs of PWD are fully taken into account in its social organization (Oliver; 1996,).To address challenges facing them towards inclusivity of SWD,HE institutions need to understand the logic behind the social model of disability.

\subsection{Challenges Affecting Readiness for Access to HE by SWD in Kenya}

Universities face challenges of stereotyping SWD among some staff members and students(Healey et al.(2011).Negative attitudes toward disability and the provision of accommodations can be summarized as an attitudinal challenge(Michalko,2002).This leads to failure to disclose disabilities by students(Madriaga, Hanson ,Heaton, Kay, Newitt \& Walker 2010)), a factor which affects the database for SWD (Githnji, 2016; Wanja, 2015).That means that universities find it a challenge to plan for SWD's needs. Disabilities are experienced differently even if they were in the same category, there is therefore the challenge of provision of individualized environments of access( Thomas \&O'Hanlon . 2004 ). Some researchers have cited lack of faculty knowledge and awareness of the issues that face these students(Sniatecki, J; Perry, H; \& Snell,2015).Lecturer's competencies in disability issues is also a challenge in $\mathrm{HE}$ institutions ( $\mathrm{Ng}$ Chiaw Gee ,2018).Limited awareness on disability issues poses a challenge within universities(Oliver,1990).From reviewing this literature the researcher established that none of it has linked institutional challenges with access to higher education by SWD. This study attempted to focus on this aspect.

\section{Research Design and Methodology}

This study has applied a case study basic qualitative research method of a descriptive nature( Gay, Mills, \& Airasian ,2012). It is based on the social model of disability as its theoretical framework and constructivist (interpretive) paradigm(Mertens, 2010).The research applied Information Power model (Malterud et al, 2015)and purposive sampling( Patton, 2002) technique because of the characteristics of the target population.

\subsection{Study Population and sample size}

The study was conducted in (6) public universities in Kenya. Two hundreds and two (202) students with disabilities undertaking studies at various levels, 6 Registrars of academic, 6 deans of students and 46 lecturers participated in the study.They were selected using purposive sampling method (Patton, 2002). The snowball purposive sampling method helped to reach lecturers and SWD.

\subsection{Research Instruments}

The research instruments comprised of three questionnaire an observation checklist and a focus group discussion. There was a questionnaire for students with disabilities, a questionnaire for lecturers, a questionnaire for deans of students and one for the registrar's academic. One observation checklist was used. The FGD was conducted at the end of data collection for only SWD.This is because it was easy to form a group of students because they ere more in number and easy to assemble than it was with lecturers and administrators. The various tools helped in the validation process.

\section{Discussion of the Findings}

This section tackles the discussion and presentation of the findings.

\subsection{Institutional challenges and Access to HE by SWD}

Table 1 shows how administrators, lecturers and students with disabilities responded as pertains to the challenges that universities experienced in terms of readiness for access to education for SWD. There were challenges of provision of recreational facilities to meet the needs of SWD. Most respondents saw this as a challenge. $91 \%$ of the administrators listed this as a challenge, $87 \%$ of the lecturers too, and 95\% of the SWD also listed limited provision of recreational facilities as a challenge. This could mean that there was inadequate awareness about the need for these facilities by SWD on the part of the concerned staff Sniatecki, et al,(2015). Alternatively a negative attitude towards provision of these facilities for these students by those concerned as qualified by Michalko( 2002) is implied.The lack of faculty knowledge and awareness of the issues that face these student is actually a challenge faced by these institutions as seen from the responses. Following this responses the researcher concluded that competencies among the lecturers to meet the learning needs of SWD was also an issue that affected their access to HE. This compares with the observation by Ng Chiaw Gee (2018). All the respondents showed that expertise in disability needs was limited among most lecturers. 91\% of administrators reported that there was limited expertise in disability needs, $65 \%$ of lecturers and $82 \%$ of SWD reported the same. The respondents equally agreed that there were inadequate lecturers who had specialized in special needs. Eighty two percent( $82 \%$ )of the administrators agreed with this, $78 \%$ of the lecturers reported so and $69 \%$ of SWD said that there were inadequate lecturers with SNE specialization. Responses on the status of facilities such as infrastructure,transport, lack of 
disability audits led the researcher to make inferences on disability awareness, attitudes and knowledge on the part of university faculty and staff. It also implied that there were limited financial resources to meet.SWD needs. Lack of disability audits also implied poor data management.

\section{Institutional challenges and access}

Table 1 Administrators', lecturers' and students' response on the challenges of universities towards access for SWD

\begin{tabular}{|c|c|c|c|c|c|c|c|c|c|c|c|c|c|c|c|c|c|c|}
\hline \multirow{2}{*}{ Challenge } & \multicolumn{6}{|c|}{ Admin response } & \multicolumn{4}{|c|}{ Lecturer's Response } & \multicolumn{7}{|c|}{ SWD response } & \multirow[b]{2}{*}{$\mathrm{T} \%$} \\
\hline & $\mathrm{Y}$ & $\mathrm{N}$ & $\mathrm{T}$ & $\mathrm{Y} \%$ & N\% & $\mathrm{T} \%$ & $\mathrm{Y}$ & $\mathrm{N}$ & $\mathrm{T}$ & $\mathrm{Y} \%$ & N\% & $\mathrm{T} \%$ & $\mathrm{Y}$ & $\mathrm{N}$ & $\mathrm{T}$ & $\mathrm{Y} \%$ & N\% & \\
\hline $\begin{array}{l}\text { Lack of sports facilities for } \\
\text { SWD }\end{array}$ & 8 & 3 & 11 & 72 & 28 & 100 & 40 & 6 & 46 & 87 & 13 & 100 & 104 & 98 & 202 & 51 & 49 & 100 \\
\hline $\begin{array}{l}\text { Lack games instructors for } \\
\text { SWD }\end{array}$ & 10 & 1 & 11 & 91 & 9 & 100 & 38 & 8 & 46 & 83 & 17 & 100 & 106 & 96 & 202 & 52 & 48 & 100 \\
\hline $\begin{array}{l}\text { Lack of adaptive transport } \\
\text { facilities/no disability audits }\end{array}$ & 9 & 2 & 11 & 82 & 18 & 100 & 42 & 4 & 46 & 91 & 9 & 100 & 114 & 88 & 202 & 56 & 44 & 100 \\
\hline Inaccessible infrastructure & 9 & 2 & 11 & 82 & 18 & 100 & 40 & 6 & 46 & 87 & 13 & 100 & 196 & 6 & 202 & 97 & 23 & 100 \\
\hline $\begin{array}{lll}\text { Limited expertise } & \text { on } \\
\text { disability needs } & \end{array}$ & 10 & 1 & 11 & 91 & 9 & 100 & 30 & 16 & 46 & 65 & 35 & 100 & 120 & 82 & 202 & 59 & 41 & 100 \\
\hline $\begin{array}{l}\text { Inadequate lecturers for } \\
\text { special needs }\end{array}$ & 9 & 2 & 11 & 82 & 18 & 100 & 36 & 10 & 46 & 78 & 22 & 100 & 140 & 62 & 202 & 69 & 31 & 100 \\
\hline $\begin{array}{l}\text { Inadequate knowledge in } \\
\text { SNE among lecturers }\end{array}$ & 10 & 1 & 11 & 91 & 9 & 100 & 42 & 4 & 46 & 95 & 5 & 100 & 196 & 6 & 202 & 97 & 3 & 100 \\
\hline $\begin{array}{ll}\text { Inadequate } & \text { tea/lrning } \\
\text { resources } & \end{array}$ & - & - & - & - & - & - & 43 & 3 & 46 & 93 & 7 & 100 & 190 & 12 & 202 & 94 & 6 & 100 \\
\hline Limited recreational facilities & 10 & 1 & 11 & 91 & 9 & 100 & 40 & 6 & 46 & 87 & 13 & 100 & 192 & 42 & 202 & 95 & 5 & 100 \\
\hline Limited disability awareness & 8 & 3 & 11 & 73 & 27 & 100 & 34 & 12 & 46 & 73 & 37 & 100 & 170 & 32 & 202 & 84 & 16 & 100 \\
\hline
\end{tabular}

\section{Summary, Conclusion and Recommendations}

The study set out to determine challenges experienced in Public universities towards readiness for access (inclusion) to higher education by students with disabilities in Kenya with a view of making recommendations for action to universities and relevant agencies based on the findings.

\subsection{Summary}

The study established that universities had challenges while positioning themselves for readiness to meet the needs of students with disabilities. One glaring challenge was lack of capacity among staff members on the needs of SWD. This was implied through the existence of other challenges such as lack of provision of recreational facilities to meet the needs of SWD, equipment, technological aids and other devices were insufficient, existence of infrastructure that did not meet the required disability audit standards as well as substandard transport facilities. The fact that there was lack of priority on disability readiness pointed to a more underlying challenge of attitude. If disability issues took a back seat then SWD are not regarded highly in these institutions. Lecturer's competence to meet the learning needs of SWD was also a challenge that affected student's access to education. Most lecturers who taught SWD indicated that they do not have the basic training about the needs of students with disability. They end up delivering instruction without disability inclusiveness in mind. Likewise it was established that expertise in alternative technology (AT) in disability needs was limited among most lecturers. This factor led to less disability inclusiveness in their pedagogical skills.Poor accessibility of infrastructure was a pointer to a lack of capacity on standards for disability infrastructure and limited financial resources to address disability readiness. In most universities, infrastructure was not designed with consideration for disability inclusiveness. Transport provision was also a challenge because vehicles, especially buses had no provision for access of those with mobility and visual impairments. These factors existed because of limited expertise on disability needs among staff of the university. University administrators indicated that their universities subscribed to the universal design principles but on observation there was no evidence of practice of the same. Respondents reported that no disability audits are done either internally or by third party arrangement in most universities.

\section{1 conclusion}

This study concluded that Universities in Kenya have capacity, technical know -how and resource scarcity challenges that need to be addressed in order to be able to face the issue of readiness for access to education by SWD.

\subsection{Recommendation}

The study recommends that universities need to adopt the Universal Design Model for their infrastructure, Teaching/learning and curricula designs by establishing the department of UD in their organizational structure. This will enable them to address their challenges systematically. 
Figure 2 Recommended Universal Design Departmental Management Structure

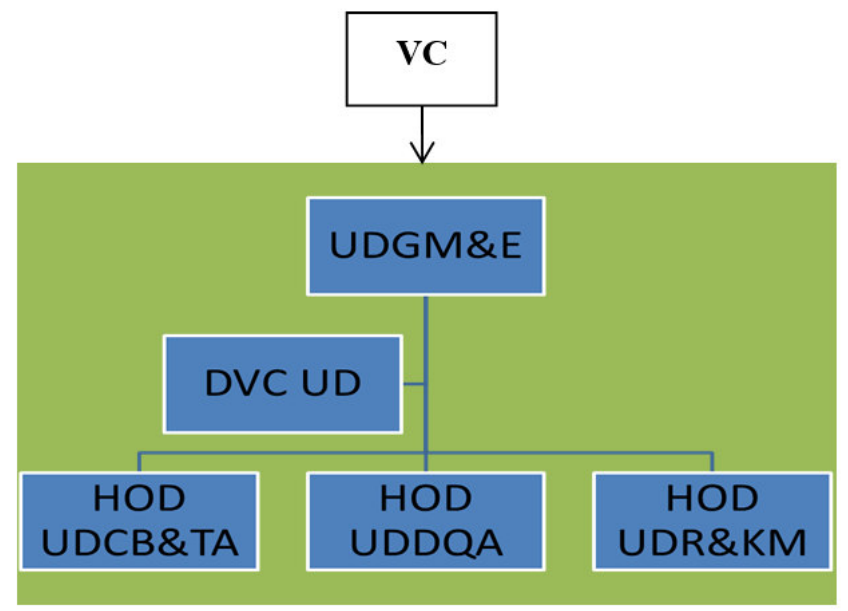

UDGM\&E: $\quad$ Universal Design Governance Monitoring and evaluation

DVC UD:

Deputy Vice chancellor Universal Design

HOD UDCB\&TA: Head of Department Universal Design Capacity Building \& Technical Assistance HOD UDDQA: Head of department Universal Design, Design and Quality Assurance HOD UDR\&KM:

Head of Department Universal Design Research and knowledge Management

\section{References}

Barnes, C. 1991: Disabled People in Britain and Discrimination: A Case for Anti-discrimination Legislation. London: Hurst and Co. in association with the British Council of Organizations of Disabled People.

Barnes, C. 1999.A Working Social Model? Disability and Work in the 21st Century, Disability Studies Conference, Edinburgh

Gay, R., Mills, E., \& Airasian P. (2012), Educational Research Competencies for Analysis and Applications, (10th edition). Pearson Education, Inc., New York.

Githinji J.W (2015), Access to university education for Persons with Disabilities: towards inclusion. (Master's thesis in law), University of Nairobi.

Madriaga M, Hanson K,Heaton C, Kay H, Newitt S Walker A ( 2010),Confronting similar challenges? Disabled and non - disabled students' learning and assessment experiences DOI: 10.1080/03075070903222633

Malterud1 K.Siersma1 V.D \& Guassora AD,(2015) Sample Size in Qualitative Interview Studies: Guided by Information Power Qualitative Health Research sagepub.com/journalsPermissions.nav DOI: 10.1177/1049732315617444 qhr.sagepub.com

Matshedisho, (2007) Access to higher education for disabled students in South Africa: a contradictory conjuncture of benevolence, rights and the social model of disability, Disability \& Society, 22:7, 685-699,

Mertens, D. M. (2010). Research and evaluation in education and psychology: Integrating diversity with quantitative, qualitative, and mixed methods. (3rd Ed.) Thousand Oaks, CA: Sage

Michalko, R. (2002). The difference that disability makes. Philadelphia: Temple University Press.

Mukhwana E (2016), State Of University Education in Kenya, Commission For University Education, Nairobi

Ng Chiaw G (2018), The Impact of Lecturers' Competencies on Students' Satisfaction, Journal of Arts \& Social Sciences Vol 1, Issue 2, 74-86 (2018)

Oliver, M .( 1990) The Politics of Disablement. Basingstoke: Macmillan.

Oliver, M. (1996)Understanding Disability: From Theory to Practice. London: Macmillan.

Republic of Kenya (2007) Kenya National Survey for Persons with Disabilities, National Coordinating Agency for Population and Development, Nairobi

Republic of Kenya (2008) Kenya's Vision 2030, a Globally Competitive and Prosperous Kenya, GP, Nairobi

Sniatecki, J; Perry, H; \& Snell,(2015). "Faculty attitudes and knowledge regarding college students with disabilities" Healthcare Studies Faculty Publications. https://digitalcommons.brockport.edu/hsc_facpub/5

Thomas G \&O’Hanlon C (. 2004)Special Teaching For Special Children? Pedagogies For Inclusion: A Pedagogy for inclusion McGraw-Hill Education (UK)

Tshifhiwa R.M (2016).Educational Support of Students with Disabilities at Institutions of Higher Learning in South Africa: A Case Study of the University Of Venda University Of Limpopo, Published Thesis

UNCRPD (2006). Convention on the Rights of Persons with Disabilities and optional Protocol www.un.org/disabilities/documents/convention/convoptprot-e.pdf Accessed on 21.4.2019

UNDP (2019), Sustainable Development Goals, 2030 United Nations, New York, 
UNGA, (2015), United Nations Sustainable Development Summit 2015, Sustainable Development Goals, Switzerland ,Geneva 20

Wanja A W(2016),Policy And Provision Of Learning Supports And Accommodations For Students With Disabilities In Kenyan Public Universities( Unpublished Thesis)

Wayne T. O, (2004) Perspectives on Disability, Discrimination, Accommodations, and Law: A Comparison of the Canadian and American Experience.

WHO\&World Bank, (2011) Learning for All: Investing in People's Knowledge and Skills to Promote Development, World Bank Group Education Strategy 2020 